\title{
Prognostic and functional impact of perioperative LAMA/LABA inhaled therapy in patients with lung cancer and chronic obstructive pulmonary disease
}

Yoko Azuma', Atsushi Sano' ', Takashi Sakai', Satoshi Koezuka'', Hajime Otsuka', Naobumi Tochigi², Kazutoshi Isobe ${ }^{3}$, Susumu Sakamoto ${ }^{3}$, Yujiro Takai ${ }^{3}$ and Akira lyoda ${ }^{1^{*}}$ (1)

\begin{abstract}
Background: Chronic obstructive pulmonary disease (COPD) is an important risk factor for postoperative complications and mortality. To determine the effects of perioperative combination therapy, using a long-acting muscarinic antagonist (LAMA) and a long-acting $\beta_{2}$ agonist (LABA), on preoperative lung function, postoperative morbidity and mortality, and long-term outcome in COPD patients.

Methods: Between January 2005 and October 2019, 130 consecutive patients with newly diagnosed COPD underwent surgery for lung cancer. We conducted a retrospective review of their medical record to evaluate that LAMA/ LABA might be an optimal regimen for patients with COPD undergoing surgery for lung cancer. All patients were received perioperative rehabilitation and divided into 3 groups according to the type of perioperative inhaled therapy and management: LAMA/LABA $(n=64)$, LAMA $(n=23)$ and rehabilitation only (no bronchodilator) $(n=43)$. We conducted a retrospective review of their medical records.

Results: Patients who received preoperative LAMA/LABA therapy showed significant improvement in lung function before surgery $\left(p<0.001\right.$ for both forced expiratory volume in $1 \mathrm{~s}\left(\mathrm{FEV}_{1}\right)$ and percentage of predicted forced expiratory volume in $1 \mathrm{~s}$ (FEV \%pred). Compared with patients who received preoperative LAMA therapy, patients with LAMA/LABA therapy had significantly improved lung function ( $\triangle F E V_{1}$, LAMA/LABA 223.1 mL vs. LAMA 130.0 mL, $\triangle \mathrm{FEV}_{1} \%$ pred, LAMA/LABA $10.8 \%$ vs. LAMA 6.8\%; both $\left.p<0.05\right)$. Postoperative complications were lower frequent in the LAMA/LABA group than in the LAMA group ( $p=0.007$ ). In patients with moderate to severe air flow limitation $(n=61)$, those who received LAMA/LABA therapy had significantly longer overall survival and disease-free survival compared with the LAMA ( $p=0.049, p=0.026)$ and rehabilitation-only groups $(p=0.001, p<0.001)$. Perioperative LAMA/LABA therapy was also associated with lower recurrence rates (vs. LAMA $p=0.006$, vs. rehabilitation-only $p=0.008)$.
\end{abstract}

Conclusions: We believe this treatment combination is optimal for patients with lung cancer and COPD.

Keywords: Lung cancer, COPD, LAMA/LABA therapy, Perioperative management

\footnotetext{
*Correspondence: aiyoda@med.toho-u.ac.jp

1 Division of Chest Surgery, Department of Surgery, Toho University School of Medicine, 6-11-1 Omori-nishi, Ota-ku, Tokyo 143-8541, Japan Full list of author information is available at the end of the article
}

\section{Background}

Chronic obstructive pulmonary disease (COPD) is a chronic inflammatory disease of the airways characterized by persistent symptoms such as cough, sputum 
production, progressive breathlessness, and airflow obstruction [1]. Patients with lung cancer have a sixfold greater risk of having COPD than do matched smokers [2]. Although eligible patients with lung cancer receive a survival benefit from surgical resection, COPD is an important patient-related risk factor for postoperative complications and mortality [3]. Patients with COPD often have nonspecific airway hyperactivity, suggesting the presence of bronchospasm or latent respiratory tract infection. It is important to alleviate peripheral airway obstruction and to reduce airway secretions to improve surgical outcomes [4-6]. The combination of smoking cessation, physical therapy, and the use of bronchodilators reportedly reduces postoperative complications and improves surgical outcomes in patients with lung cancer and COPD $[7,8]$.

Long-acting muscarinic antagonists (LAMAs) prevent the neurotransmitter acetylcholine from binding to muscarinic receptors, leading to relaxation of the airway smooth muscle [9]. Long-acting $\beta_{2}$ agonists (LABAs) act on $\beta_{2}$-adrenergic receptors and cause relaxation of the smooth muscle [10]. Patients who receive combined LAMA/LABA therapy for COPD show superior improvement in lung function and clinical outcomes than those who receive bronchodilator monotherapy [11]. Combined LAMA/LABA therapy also leads to a lower incidence of pneumonia than the combination of inhaled corticosteroids (ICS) and a LABA [11].

Because the prognosis of patients with lung cancer complicated by COPD is reportedly poor [7], it is important to provide respiratory care for an extended duration, not just during the perioperative period. The aim of this study is to determinate the effects of perioperative LAMA/LABA therapy on preoperative lung function, postoperative morbidity and mortality, and long-term prognosis for patients with COPD and lung cancer. We hypothesize that perioperative LAMA/LABA therapy will improve surgical outcomes.

\section{Methods}

This study was approved by the Ethics Committee of Faculty of Medicine, Toho University (A19039_27128_25095_25047).

\section{Study design and population}

We performed a retrospective review of the medical records of patients who underwent surgical resection of lung cancer at Toho University Hospital between January 2005 and October 2019. We included patients over the age of 40 with both airflow limitation (AFL) and a smoking history of greater than 10 pack-years. Patients who had characteristics of asthma such as wheezing, shortness of breath, chest tightness, or allergic conditions were excluded. We defined AFL as a ratio of expiratory volume in $1 \mathrm{~s}\left(\mathrm{FEV}_{1}\right)$ to forced vital capacity (FVC) less than $70 \%$, as determined by spirometry at the patient's initial visit. We excluded patients with a history of asthma or a history of inhaled therapy, and those who were missing data.

All patients with newly defined COPD received perioperative rehabilitation. The patients were divided into 3 groups according to their perioperative management: a LAMA/LABA group, a LAMA group, and a group that did not receive bronchodilators (No-BD group). The severity of AFL was classified according to the spirometric grades outlined by the Global Initiative for Chronic Obstructive Lung Disease (GOLD) [12].

Classification criteria for the three groups are based on changes in perioperative management for COPD patients as follows.

In our institute, we have executed perioperative respiratory rehabilitation and perioperative LAMA therapy for COPD patients with moderate to severe AFL since 2005 to March 2013. Since April 2013, when LABA have been developed for COPD, perioperative inhaled agent has been changed to LAMA/LABA. Eventually, therapeutic target has been expanded to COPD patients with mild AFL since July 2015. From January 2005 to June 2015, COPD patients with mild AFL, glaucoma, or severe benign prostatic hyperplasia were executed perioperative respiratory rehabilitation only.

Reassessment of respiratory function is performed on patients who received bronchodilators 1 or 2 days before surgery during hospitalization. All patients use inhaled medication early in the morning and have a respiratory function test in the afternoon.

\section{Postoperative complications}

Pneumonia was defined as the presence of at least 3 of the following: a persistent lung infiltrate on chest radiography, chest computed tomography or both; a temperature of $>37.5{ }^{\circ} \mathrm{C}$; and a leukocyte count $>10,000 / \mathrm{mm}^{3}$. Acute respiratory failure was defined as postoperative ventilator dependence $>12 \mathrm{~h}$ or reintubation for mechanical ventilation. Prolonged air leakage was defined as the continuation of air leakage for more than 7 days after surgery. Atrial fibrillation was diagnosed by electrocardiography and required to persist for at least $1 \mathrm{~h}$.

\section{Statistical analysis}

The data were presented as the mean \pm standard deviation (SD) or as the median value with interquartile ranges. Categorical variables were shown as the percentage of the sample. Comparisons between 2 groups were assessed using Student's t-test for normally distributed variables or using the Mann-Whitney $U$ test for nonnormally distributed variables. Differences were 
considered statistically significant when the $p$ value was less than 0.05. Survival curves were prepared using the Kaplan-Meier method, and univariate comparison was performed using the log-rank test. To determine which factors were significantly associated with survival, we performed multivariate analysis using the Cox proportional hazards model. All statistical analyses were performed using JMP software, version 14.0 (SAS Institute Inc., Cary, NC, USA).

Cox hazard regression models were constructed to calculate adjusted $95 \%$ confidence intervals (CIs).

\section{Results}

\section{Patient characteristics}

Between January 2005 and October 2019, a total of 1330 patients with lung cancer underwent surgical resection at our institution. Of these, 192 patients (14.4\%) met the inclusion criteria. A total of 62 patients had at least 1 exclusion criterion (Additional file 4: Fig. 1).

A total of 130 patients with COPD who underwent surgical resection of lung cancer and who received perioperative rehabilitation were enrolled in this study. The patients were divided into 3 subgroups according to their perioperative management: the LAMA/LABA group $(n=64)$, the LAMA group $(n=23)$, and the No-BD group (rehabilitation only; $\mathrm{n}=43$ ). The main patient characteristics are summarized in Table 1. Patients who received LAMA/LABA therapy were significantly older than patients in the LAMA group $(p=0.045)$ and those in the No-BD group $(p=0.027)$. There was no significant difference between patients in the LAMA/LABA group and the other groups with regard to sex, smoking status, pack-years of smoking or comorbidities, the type of surgical procedure performed, and histology although there was a significant difference between the LAMA/LABA group and the LAMA group on pathologic staging. Most patients underwent lobectomy (LAMA/LABA, 87.5\%; LAMA, 100\%; No-BD, 93.0\%).

Pulmonary function at the initial visit was significantly worse in the LAMA group than in the LAMA/LABA group, as measured by $\mathrm{FEV}_{1}, \mathrm{FEV}_{1} / \mathrm{FVC}$, and the percentage of predicted $\mathrm{FEV}_{1}$ (FEV1\% pred) $(p<0.05$ for all). The LAMA group had a higher proportion of patients with moderate to severe AFL than the LAMA/LABA group $(p<0.001)$, while the No-BD group included a higher proportion of patients with mild AFL $(p<0.001)$.

\section{Perioperative inhaled therapy}

The components of perioperative inhaled therapy are provided in Additional file 1: Table 1. In the LAMA/ LABA group, patients received a LAMA plus a LABA $(n=11)$ or a combined LAMA/LABA agent $(n=53)$. All patients in the LAMA group received inhaled tiotropium bromide hydrate. The average duration of preoperative inhalation therapy in the LAMA/LABA group and the LAMA group was 27.7 days and 24.5 days $(p=0.500)$, respectively. The postoperative inhalation period was 396.6 days and 827.2 days $(p=0.002)$, respectively (Additional file 1: Table 1).

\section{Improvement in lung function with preoperative inhaled LAMA/LABA therapy}

We reassessed lung function 1 or 2 days before surgery. The values for $\mathrm{FEV}_{1}$ and $\mathrm{FEV}_{1}$ \%pred were significantly improved in the LAMA/LABA group (both $p<0.001$; Fig. 1a, b). In the LAMA/LABA group, the treatment response tended to correlate with the severity of AFL. The patients with severe AFL showed an excellent response compared with patients with mild or moderate AFL (vs. mild AFL $p=0.023$, vs. moderate $p=0.048$; Fig. 1c). We also compared the improvement in lung function between the LAMA/LABA group and the LAMA group. The increases in $\mathrm{FEV}_{1}$ and $\mathrm{FEV}_{1}$ \%pred were significantly higher for LAMA/LABA therapy than for LAMA therapy $\left(\triangle \mathrm{FEV}_{1}, 223.1 \mathrm{~mL}\right.$ vs. $130.0 \mathrm{~mL}$; $p=0.007 \Delta \mathrm{FEV}_{1} \%$ pred, $10.8 \%$ vs. $6.8 \%$; $p=0.019$; Fig. $2 \mathrm{a}$, b). The proportion of excellent treatment response was also higher in the LAMA/LABA group $\left(\Delta \mathrm{FEV}_{1}>200 \mathrm{~mL}\right.$, $59.4 \%$ vs. $17.4 \% ; p<0.001 \Delta \mathrm{FEV}_{1}>300 \mathrm{~mL}, 34.4 \%$ vs. $4.3 \%$; $p=0.005$; Fig. $2 \mathrm{c}$ ).

\section{Postoperative morbidity and mortality}

Postoperative complications and mortality are summarized in Table 2. Postoperative complications were more frequent in the LAMA group than in the LAMA/ LABA group $(p=0.007)$. The proportion of patients who required home oxygen therapy was higher in the LAMA group than in the LAMA/LABA group $(p=0.008)$. Prolonged air leakage was more frequent in the No-BD group than in the LAMA/LABA group $(p=0.012)$. Only the LAMA/LABA group had no mortality at 90 days.

\section{Survival analysis of all patients}

Although a comparable proportion of patients received adjuvant chemotherapy or treatment for recurrence in all groups (Table 3), the recurrence rate was significantly lower in the LAMA/LABA group compared with both the LAMA group $(p=0.006)$ and the No-BD group $(p=0.008)$ (Table 3).

Five patients $(7.8 \%)$ in the LAMA/LABA group, 14 patients $(60.8 \%)$ in the LAMA group, and 20 patients $(46.5 \%)$ in the No-BD group died during the study period. The causes of death for these 39 patients are given in Additional file 2: Table 2. Lung-cancer related death was the most frequent cause in all groups. No patients in the LAMA/LABA group died of pneumonia. 
Table 1 Patient characteristics in all patients

\begin{tabular}{|c|c|c|c|c|c|}
\hline & \multicolumn{5}{|c|}{ Patients with COPD $(n=130)$} \\
\hline & LAMA/LABA & LAMA & $p$ value* & No-BD & $P$ value $* *$ \\
\hline & $n=64$ & $n=23$ & & $n=43$ & \\
\hline Age & $73.4 \pm 6.7$ & $70.6 \pm 6.5$ & 0.045 & $70.5 \pm 6.2$ & 0.027 \\
\hline \multicolumn{6}{|l|}{ Sex } \\
\hline Male & $50(78.1)$ & $19(82.6)$ & 0.644 & $39(90.7)$ & 0.088 \\
\hline Female & $14(21.9)$ & $4(17.4)$ & & $4(9.3)$ & \\
\hline \multicolumn{6}{|l|}{ Smoking status } \\
\hline Current smoker & $25(39.0)$ & $11(47.8)$ & 0.466 & $18(41.9)$ & 0.772 \\
\hline Ex-smoker & $39(61.0)$ & $12(52.2)$ & & $25(58.1)$ & \\
\hline Tobacco, pack-years & $53.2 \pm 27.3$ & $60.6 \pm 29.4$ & 0.301 & $63.8 \pm 40.2$ & 0.052 \\
\hline \multicolumn{6}{|l|}{ Pulmonary function } \\
\hline $\mathrm{FEV}_{1}(\mathrm{~mL})$ & $1787.5 \pm 558.8$ & $1429.5 \pm 412.5$ & 0.005 & $2168.8 \pm 535.2$ & $<0.001$ \\
\hline $\mathrm{FEV}_{1} / \mathrm{FVC}(\%)$ & $58.3 \pm 9.6$ & $53.4 \pm 11.4$ & 0.049 & $61.4 \pm 10.2$ & 0.106 \\
\hline FEV $\%$ pred (\%) & $85.3 \pm 22.6$ & $64.3 \pm 12.4$ & $<0.001$ & $94.6 \pm 2.9$ & 0.017 \\
\hline \multicolumn{6}{|l|}{ Severity of AFL } \\
\hline Mild & $32(50.0)$ & $1(4.4)$ & $<0.001$ & $36(83.7)$ & $<0.001$ \\
\hline Moderate to severe & $32(50.0)$ & $22(95.6)$ & & $7(16.3)$ & \\
\hline \multicolumn{6}{|l|}{ Comorbidities } \\
\hline Cardiovascular disease & $38(59.4)$ & $13(56.5)$ & 0.812 & $33(76.7)$ & 0.575 \\
\hline Diabetes mellitus & 17 (26.6) & $6(26.1)$ & 0.964 & $12(27.9)$ & 0.878 \\
\hline \multicolumn{6}{|l|}{ Surgical procedure } \\
\hline Pneumonectomy & $1(1.6)$ & 0 & 0.367 & 0 & 0.844 \\
\hline Lobectomy & $56(87.5)$ & $23(100.0)$ & & $40(93.0)$ & \\
\hline Segmentectomy & $2(3.1)$ & 0 & & $1(2.3)$ & \\
\hline Partial resection & $5(7.8)$ & 0 & & $2(4.7)$ & \\
\hline \multicolumn{6}{|l|}{ Histology } \\
\hline Adenocarcinoma & $31(48.4)$ & $6(26.1)$ & 0.172 & $26(60.5)$ & 0.450 \\
\hline Squamous cell carcinoma & $28(43.8)$ & $14(60.9)$ & & $15(34.9)$ & \\
\hline Other & $5(7.8)$ & $3(13.0)$ & & $2(4.7)$ & \\
\hline \multicolumn{6}{|l|}{ Pathologic staging } \\
\hline I & $50(78.1)$ & $11(47.8)$ & 0.014 & $33(76.7)$ & 0.411 \\
\hline$\|$ & $8(12.5)$ & $9(39.1)$ & & $3(7.0)$ & \\
\hline III & $6(9.4)$ & $3(13.0)$ & & $7(16.3)$ & \\
\hline Recurrence (present) & $7(10.9)$ & $11(47.8)$ & $<0.001$ & $15(34.9)$ & 0.003 \\
\hline
\end{tabular}

Data are presented as $\mathrm{n}(\%)$ or as mean $\pm \mathrm{SD}$

COPD Chronic obstructive pulmonary disease; $L A M A$ long-acting muscarinic antagonists; $L A B A$ long-acting $\beta 2$-agonists; $B D$ bronchodilator; $F E V 1$ forced expiratory volume in $1 \mathrm{~s}$; FEV1\%pred percentage of predicted forced expiratory volume in $1 \mathrm{~s} ; F V C$ forced vital capacity; $A F L$ airflow limitation

* Significance of LAMA/LABA versus LAMA

** Significance of LAMA/LABA versus No-BD

The cumulative OS at 5 years was $79.8 \%$ in the LAMA/ LABA group, $53.2 \%$ in the LAMA group, and $51.7 \%$ in the No-BD group (Fig. 3a). The DFS at 5 years was $70.8 \%, 39.2 \%$, and $39.9 \%$, respectively (Fig. $3 \mathrm{~b}$ ). The patients in the LAMA/LABA group had significantly longer OS and DFS than patients in the LAMA group ( $p=0.023,95 \% \mathrm{CI}$ : $0.11-0.91 ; p=0.015,95 \% \mathrm{CI}$ :
0.16-0.82), and longer DFS than patients in the No-BD group ( $p=0.020$, 95\%CI: $0.20-0.89$ ).

Survival analysis of patients with moderate to severe AFL We assessed the effects of perioperative inhaled LAMA/LABA therapy on the prognosis of patients with moderate to severe AFL. A total of 51 patients 

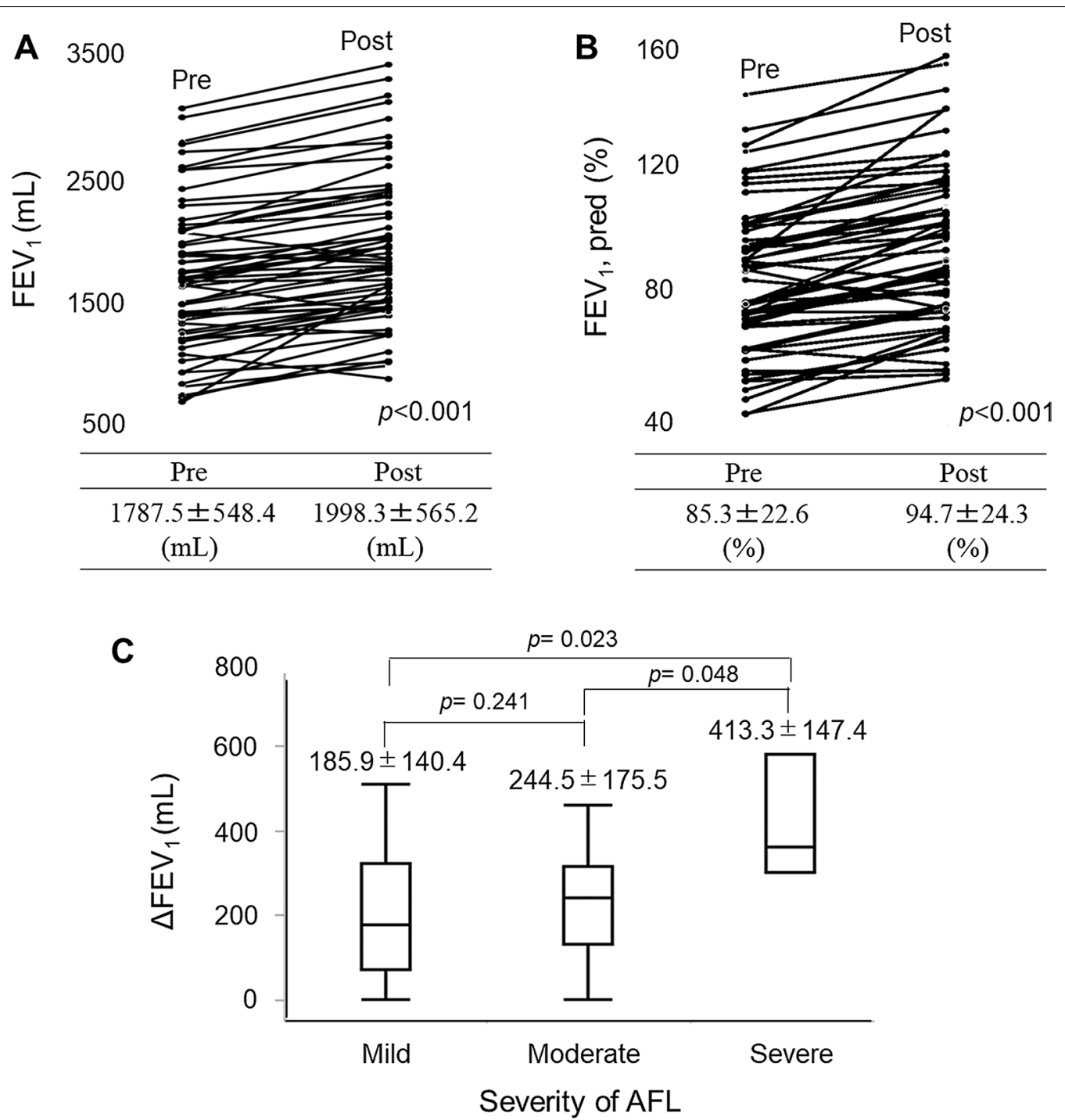

Fig. 1 Changes in lung function with preoperative LAMA/LABA therapy. a Changes in forced expiratory volume in $1 \mathrm{~s}\left(\mathrm{FEV}_{1}\right)$. b Changes in percentage of predicted $\mathrm{FEV}_{1}$ ( $F E V_{1} \%$ pred). $\mathbf{c}$ Improvement in $\mathrm{FEV}_{1}$ by severity of airflow limitation (AFL)

with moderate to severe AFL were included in the study. Of these, 32 were in the LAMA/LABA group, 12 were in the LAMA group, and 7 were in the No-BD group. Patient characteristics are given in Table 3. There was no significant difference between patients in the LAMA/LABA group and the other groups in regard to age, sex, smoking status, severity of AFL, surgical procedure, preoperative comorbidities or treatment for recurrence although there was a significant difference between the LAMA/LABA group and the LAMA group on pathologic staging. A comparable proportion of patients received adjuvant chemotherapy in all groups. As seen in the analysis of COPD patients of all severities, the recurrence rate was significantly lower in the
LAMA/LABA group compared with the LAMA group $(p=0.006)$ and the No-BD group $(p=0.008$; Table 3$)$.

The OS in the LAMA/LABA, LAMA, and No-BD groups at 5 years was $82.7 \%, 55.8 \%$, and $28.6 \%$, respectively (Fig. 4a). The DFS at 5 years was $75.3 \%, 41.1 \%$, and $14.3 \%$ (Fig. 4b). The patients in the LAMA/LABA group had significantly better OS and DFS compared with the LAMA group ( $p=0.049$, 95\%CI: 0.08-0.98; $p=0.026$, 95\%CI:0.11$0.90)$ and with the No-BD group ( $p=0.001,95 \%$ CI: $0.03-$ $0.53 ; p<0.001,95 \%$ CI: 0.04-0.45). 

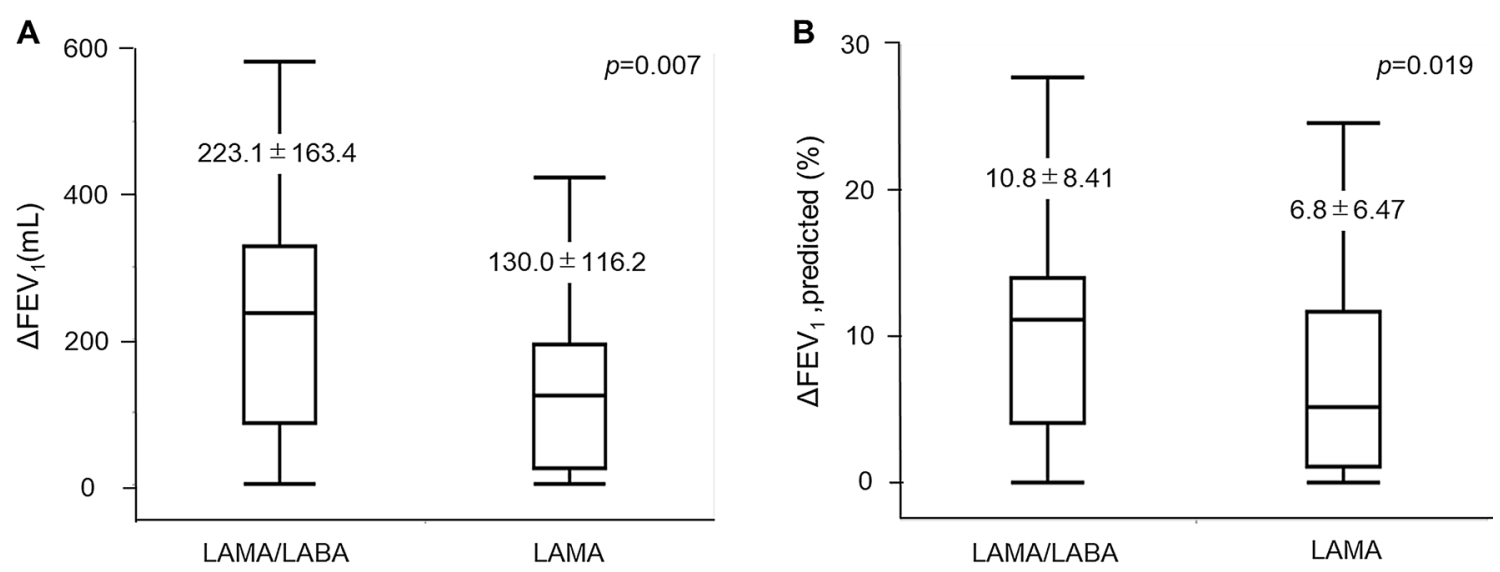

C

\begin{tabular}{cccc}
\hline & $\begin{array}{c}\text { LAMA/LABA } \\
(\mathrm{n}=64)\end{array}$ & $\begin{array}{c}\text { LAMA } \\
(\mathrm{n}=23)\end{array}$ & $p$ \\
\hline Improvement value of $\mathrm{FEV}_{1}$ & & & \\
$>200 \mathrm{~mL}$ & $38(59.4 \%)$ & $4(17.4 \%)$ & $<.001$ \\
$>300 \mathrm{~mL}$ & $22(34.4 \%)$ & $1(4.3 \%)$ & 0.005 \\
\hline
\end{tabular}

Fig. 2 Comparison of improvement in lung function between the LAMA/LABA and LAMA groups. a Improvement in FEV ${ }_{1}$. $\mathbf{b}$ Improvement in

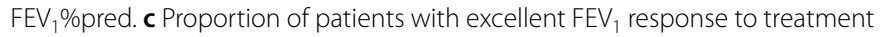

Table 2 Postoperative complications and mortality

\begin{tabular}{|c|c|c|c|c|c|}
\hline & \multicolumn{5}{|c|}{ Patients with COPD $(n=130)$} \\
\hline & LAMA/LABA & LAMA & $p$ value* & & $p$ value ${ }^{* *}$ \\
\hline & $\mathrm{n}=64$ & $\mathrm{n}=\mathbf{2 3}$ & & $n=43$ & \\
\hline \multicolumn{6}{|l|}{ Complications } \\
\hline Any & $14(21.9)$ & $12(52.2)$ & 0.007 & $16(37.2)$ & 0.083 \\
\hline Pneumonia & $7(10.9)$ & $6(26.1)$ & 0.081 & $7(16.3)$ & 0.422 \\
\hline Acute respiratory failure & $1(1.6)$ & $2(8.7)$ & 0.124 & $2(4.7)$ & 0.342 \\
\hline Prolonged air leakage & $6(9.4)$ & $5(21.7)$ & 0.126 & $11(25.6)$ & 0.012 \\
\hline Atrial fibrillation & $4(6.3)$ & $2(8.7)$ & 0.776 & $4(9.3)$ & 0.557 \\
\hline Introduction of HOT & $3(4.7)$ & $3(13.0)$ & 0.008 & 0 & 0.176 \\
\hline 30-day mortality & 0 & 0 & - & 0 & - \\
\hline 90-day mortality & 0 & $1(4.3)$ & 0.093 & $1(2.3)$ & 0.246 \\
\hline
\end{tabular}

Data are presented as $\mathrm{n}(\%)$

COPD chronic obstructive pulmonary disease; $L A M A$ long-acting muscarinic antagonists; $L A B A$ long-acting $\beta 2$-agonists; $B D$ bronchodilator; $H O T$ home oxygen therapy

* Significance of LAMA/LABA versus LAMA

** Significance of LAMA/LABA versus No-BD

\section{Univariate and multivariate analyses of beneficial factors} for long-term mortality

On multivariate analysis of all patients, histology, pathologic stage, and lymph nodes metastasis were independent prognostic factors for OS, and pathologic stage and bronchodilator were independent prognostic factors for
DFS although bronchodilator was not for OS (Additional file 3: Table 3A, 3B).

On univariate analysis of patients with moderate to severe AFL, a low pathologic stage and perioperative LAMA/LABA therapy were beneficial factors for longterm mortality on univariate analysis. On multivariate 
Table 3 Characteristics of patients with moderate to severe airflow limitation

\begin{tabular}{|c|c|c|c|c|c|}
\hline & \multicolumn{5}{|c|}{ Patients with moderate to severe AFL $(n=61)$} \\
\hline & \multirow{2}{*}{$\begin{array}{l}\text { LAMA/LABA } \\
n=32\end{array}$} & \multirow{2}{*}{$\begin{array}{l}\text { LAMA } \\
\mathrm{n}=22\end{array}$} & \multirow[t]{2}{*}{$p$ value* } & \multirow{2}{*}{$\begin{array}{l}\text { No-BD } \\
n=7\end{array}$} & \multirow[t]{2}{*}{$p$ value $* *$} \\
\hline & & & & & \\
\hline Age & $72.2 \pm 6.7$ & $70.8 \pm 6.6$ & 0.236 & $69.9 \pm 5.6$ & 0.406 \\
\hline Sex & & & 0.804 & & 0.929 \\
\hline Male & $27(84.4)$ & $18(81.8)$ & & $6(85.7)$ & \\
\hline Female & $5(15.6)$ & $4(18.2)$ & & $1(14.3)$ & \\
\hline Smoking status & & & 0.412 & & 0.262 \\
\hline Current smoker & $11(34.4)$ & $10(45.5)$ & & $4(57.1)$ & \\
\hline Ex-smoker & $21(65.6)$ & $12(54.5)$ & & $3(42.9)$ & \\
\hline Severity of AFL & & & 0.344 & & 0.399 \\
\hline Moderate & $29(90.6)$ & $18(81.8)$ & & $7(100)$ & \\
\hline Severe & $3(9.4)$ & $4(18.2)$ & & 0 & \\
\hline \multicolumn{6}{|l|}{ Comorbidities } \\
\hline Cardiovascular disease & $16(50.0)$ & $13(59.1)$ & 0.510 & $6(85.7)$ & 0.084 \\
\hline Diabetes mellitus & $6(18.8)$ & $6(27.3)$ & 0.459 & $3(42.9)$ & 0.170 \\
\hline Surgical procedure & & & 0.098 & & 0.887 \\
\hline Lobectomy & $26(81.3)$ & $22(100)$ & & $6(85.7)$ & \\
\hline Segmentectomy & $1(3.1)$ & 0 & & 0 & \\
\hline Partial resection & $5(15.6)$ & 0 & & $1(14.3)$ & \\
\hline Pathologic staging & & & 0.016 & & 0.148 \\
\hline । & $26(81.3)$ & $11(50.0)$ & & $4(57.1)$ & \\
\hline$\|$ & $2(6.3)$ & $8(36.4)$ & & 0 & \\
\hline III & $4(12,5)$ & $3(13.6)$ & & $3(42.9)$ & \\
\hline Adjuvant chemotherapy & $4(12.5)$ & $5(22.7)$ & 0.322 & $2(28.6)$ & 0.286 \\
\hline Recurrence (present) & $4(12.5)$ & $10(45.5)$ & 0.006 & $4(57.1)$ & 0.008 \\
\hline \multicolumn{6}{|l|}{ Treatment for recurrence } \\
\hline Anticancer drug & 2 & 7 & & 3 & \\
\hline Molecular targeted drug & 0 & 1 & & 1 & \\
\hline None & 2 & 2 & & 0 & \\
\hline
\end{tabular}

Data are presented as $\mathrm{n}(\%)$ or as mean $\pm \mathrm{SD}$

$C O P D$ chronic obstructive pulmonary disease; $L A M A$ long-acting muscarinic antagonists; $L A B A$ long-acting $\beta 2$-agonists; $B D$ bronchodilator; $A F L$ airflow limitation

analysis, perioperative LAMA/LABA therapy remained a beneficial factor (Table 4A). Only perioperative LAMA/ LABA therapy was identified as a beneficial factor for recurrence on both univariate and multivariate analyses (Table 4B).

\section{Discussion}

In patients with lung cancer, COPD is an independent risk factor for morbidity and mortality. In the present study, we clarified the efficacy of perioperative LAMA/ LABA therapy for pulmonary function, postoperative complications, and long-term prognosis in patients with newly diagnosed COPD requiring surgery for lung cancer.

The utility of perioperative bronchodilator therapy has been validated in several previous reports, but the most suitable agent has not been clarified. We previously analyzed the data of 32 patients with moderate to severe COPD and lung cancer and reported that perioperative LAMA/LABA therapy improves lung function and reduces postoperative complications to a greater degree than LAMA therapy [13]. In the present study, we assessed 130 patients with COPD of all severity levels, with similar results.

Some previous studies reported that preoperative LAMA monotherapy improves lung function or prevents postoperative respiratory complications, but other reports do not $[14,15]$. Bolukbas et al. reported that adding ICS to LAMA and LABA led to improvement in lung function and fewer respiratory complications [8]. However, the use of ICS is associated with severe pneumonia [16], and steroid use is a significant risk factor for bronchopleural fistula formation [17]. Therefore, the use of perioperative ICS is controversial. 

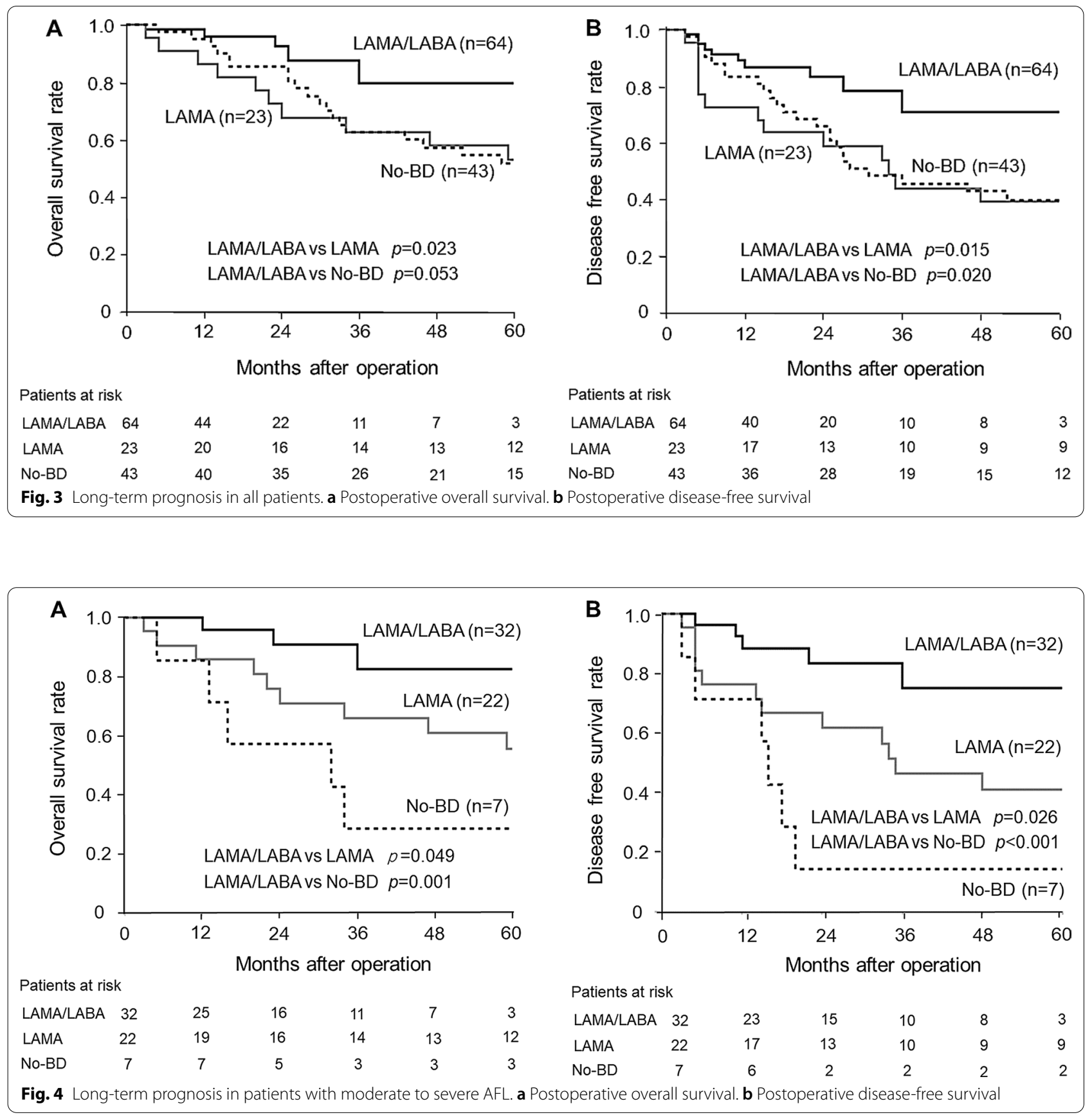

Combined LAMA/LABA therapy during the perioperative period may provide a rapid and powerful bronchodilating effect, by the dual action of LAMA and LABA without adverse events such as pneumonia.

The effect of perioperative bronchodilator use on postoperative long-term prognosis in COPD patients with lung cancer has not been reported. We found that perioperative LAMA/LABA therapy is associated with a favorable prognosis compared with LAMA therapy or rehabilitation alone, especially in patients with moderate to severe COPD.

COPD is a strong promoting factor for lung cancer, and patients with COPD have poorer postoperative long-term survival due to a higher recurrence rate and poor health status [18]. Chronic inflammation of the bronchial and alveolar mucosa [19], direct effects to DNA restoration by oxidative stress [20], and genetic mutation or variation [21] are associated with COPD 
Table 4 Univariate and multivariate analysis of favorable factors for postoperative prognosis in patients with moderate to severe AFL

\begin{tabular}{|c|c|c|c|c|c|c|}
\hline \multirow[t]{2}{*}{ Clinicopathologic variable } & \multicolumn{3}{|c|}{ Univariate analysis } & \multicolumn{3}{|c|}{ Multivariate analysis } \\
\hline & $\mathbf{R R}$ & $95 \% \mathrm{Cl}$ & $p$ value & $\mathbf{R R}$ & $95 \% \mathrm{Cl}$ & $p$ value \\
\hline \multicolumn{7}{|c|}{ A. Analysis of favorable factors for overall survival } \\
\hline Age (<75 year) & 0.88 & $0.29-2.25$ & 0.798 & - & - & - \\
\hline Histology: & & & 0.083 & - & - & - \\
\hline Squamous cell carcinoma & 1.00 & Reference & & - & - & - \\
\hline Adenocarcinoma & 0.47 & $0.18-1.14$ & 0.094 & - & - & - \\
\hline Other & 0.18 & $0.01-1.01$ & 0.051 & - & - & - \\
\hline Lymph node metastasis (absent) & 0.61 & $0.26-1.55$ & 0.290 & - & - & - \\
\hline Pathologic stage: & & & 0.027 & & & 0.106 \\
\hline । & 1.00 & Reference & & 1.00 & Reference & \\
\hline$\|$ & 2.96 & $0.99-8.25$ & 0.052 & 2.14 & $0.70-6.16$ & 0.176 \\
\hline III & 3.66 & $1.20-10.49$ & 0.024 & 3.11 & $1.00-9.13$ & 0.107 \\
\hline Bronchodilator & & & 0.010 & & & 0.048 \\
\hline LAMA/LABA & 1.00 & Reference & & 1.00 & Reference & \\
\hline LAMA or No-BD & 4.16 & $1.37-11.1$ & & 3.21 & $1.01-14.20$ & \\
\hline \multicolumn{7}{|c|}{ B. Analysis of favorable factors for disease-free survival } \\
\hline Age (<75 year) & 0.59 & $0.69-5.12$ & 0.266 & - & - & - \\
\hline Histology: & & & 0.038 & & & 0.350 \\
\hline Squamous cell carcinoma & 1.00 & Reference & & 1.00 & Reference & \\
\hline Adenocarcinoma & 0.42 & $0.17-0.96$ & 0.040 & 0.68 & $0.23-2.05$ & 0.311 \\
\hline Other & 0.16 & $0.01-0.90$ & 0.035 & 0.23 & $0.01-1.59$ & 0.148 \\
\hline Lymph node metastasis (absent) & 0.49 & $0.22-1.13$ & 0.091 & - & - & - \\
\hline Pathologic stage & & & 0.007 & & & 0.233 \\
\hline । & 1.00 & Reference & & 1.00 & Reference & \\
\hline$\|$ & 3.21 & $1.18-8.17$ & 0.024 & 1.35 & $0.39-4.90$ & 0.635 \\
\hline III & 4.13 & $1.47-11.0$ & 0.009 & 2.70 & $0.83-8.37$ & 0.278 \\
\hline Bronchodilator & & & 0.003 & & & 0.018 \\
\hline LAMA/LABA & 1.00 & Reference & & 1.00 & Reference & \\
\hline LAMA or No-BD & 3.90 & $1.55-11.8$ & & 3.29 & $1.22-10.43$ & 0.120 \\
\hline
\end{tabular}

$C O P D$ chronic obstructive pulmonary disease; $L A M A$ long-acting muscarinic antagonists; $L A B A$ long-acting $\beta 2$-agonists; $B D$ bronchodilator; $R R$ relative risk; $C I$ confidence interval

and the development of lung cancer. Recent reports propose that bronchodilators are able to inhibit inflammation and oxidative stress in mouse model [22]. Muscarinic receptors expressed on lung cancer cells can reportedly stimulate tumor growth via acetylcholine [23]. The $M_{3}$ muscarinic receptor subtype is associated with cell proliferation [23], and LAMAs have the potential to inhibit the growth of lung cancer cells as M3 receptor antagonists. Li et al. reported that indacaterol induces apoptosis in lung cancer cells harboring the epidermal growth factor receptor T790M mutation and may be a novel candidate for treatment of gefitinibresistant lung cancer [24]. Our results and these previous in vitro studies suggest the possibility of the dual anticancer effects of LAMA/LABA - prevention of cancer development and inhibition of proliferation signals of lung cancer-may contribute to a favorable prognosis and inhibition of recurrence. On the other hand, high proportion of stage I in patients who received LAMA/ LABA therapy may also affect lung cancer prognosis. Randomized controlled trials would be necessary to prove the anticancer effect by LAMA/LABA therapy.

This retrospective study has limitations and biases. The duration of bronchodilator use and the individual bronchodilators employed was inconsistent. This discrepancy about selection of bronchodilators was due to the different study periods. Differences in the study period or severely of AFL between LAMA/LABA and the other groups may have affected the postoperative complications and survival rate. Finally, changes in surgical technique, surgical methods, or anesthetic agents over the years of the study period may have affected the incidence of postoperative complications. 


\section{Conclusions}

Our data demonstrate that LAMA/LABA therapy improves not only short-term outcomes such as respiratory function and postoperative complications, but also long-term prognosis in patients with lung cancer and COPD. Perioperative combined LAMA/LABA therapy is the optimal bronchodilator for patients with COPD who require surgery for lung cancer.

\begin{abstract}
Abbreviations
COPD: Chronic obstructive pulmonary disease; LAMA: Long-acting muscarinic antagonist; LABA: Long-acting $\beta 2$ agonist; ICS: Inhaled corticosteroid; AFL: Airflow limitation; $F_{1}$ : Forced expiratory volume in $1 \mathrm{~s}$; FVC: Forced vital capacity; GOLD: Global initiative for chronic obstructive lung disease; SD: Standard deviation; Cl: Confidence interval; OS: Overall survival; BD: Bronchodilator; FEV $1 \%$ pred: Percentage of predicted expiratory volume in $1 \mathrm{~s}$; DFS: Disease-free survival.
\end{abstract}

\section{Supplementary Information}

The online version contains supplementary material available at https://doi. org/10.1186/s12890-021-01537-z.

\section{Additional file 1: Table 1. \\ Additional file 2: Table 2 \\ Additional file 3: Table 3. \\ Additional file 4: Fig. 1. Flow chart of patient selection.}

Acknowledgements

Not applicable.

\section{Authors' contributions}

YA, AS and Al contributed substantially to the study design, data analysis and interpretation, and the writing of the manuscript. YA, AS, TS, SK, HO, NT, KI, SS and $Y T$ had full access to all of the data in the study and takes responsibility for the integrity of the data and the accuracy of the data analysis. All authors read and approved the final manuscript.

\section{Funding}

This research did not receive any specific grant from funding agencies in the public, commercial, or not-for-profit sectors.

\section{Availability of data and materials}

All data generated or analyzed during this study are included in this published article and its Additional information files.

\section{Declarations}

\section{Ethics approval and consent to participate}

This study was approved by the Ethics Committee of Faculty of Medicine, Toho University (A19039_27128_25095_25047). This study was conducted based on patient data from 2005 to 2019 . Because this study was retrospective and we utilized existing information of all patients, we did not require permission to access and use the individual data/video files and we did not obtain individual consent from all patients according to Ethical Guidelines for Medical and Health Research Involving Human Subjects of the Ministry of Health, Labour and Welfare in Japan (https://www.mhlw.go.jp/file/06-Seisakujouhou-10600 000- Daijinkanboukouseikagakuka/0000080278.pdf). The presented study design was accepted by the ethics committee on the condition that.

\section{Consent for publication}

Not applicable.

\section{Competing interests}

The authors declare that they have no competing interests.

\section{Author details}

${ }^{1}$ Division of Chest Surgery, Department of Surgery, Toho University School of Medicine, 6-11-1 Omori-nishi, Ota-ku, Tokyo 143-8541, Japan. ²Department of Surgical Pathology, Toho University School of Medicine, 6-11-1 Omori-nishi, Ota-ku, Tokyo 143-8541, Japan. ${ }^{3}$ Division of Respiratory Medicine, Toho University School of Medicine, 6-11-1 Omori-nishi, Ota-ku, Tokyo 143-8541, Japan.

Received: 11 December 2020 Accepted: 11 May 2021

Published online: 21 May 2021

\section{References}

1. Lopez-Campos JL, Tan W, Soriano JB. Global burden of COPD. Respirology. 2016:21:14-23.

2. Young RP, Hopkins RJ, Christmas T, Black PN, Metcalf P, Gamble GD. COPD prevalence is increased in lung cancer, independent of age, sex and smoking history. Eur Respir J. 2009;34:380-6.

3. Win T, Jackson A, Sharples L, Groves AM, Wells FC, Ritchie AJ, et al. Relationship between pulmonary function and lung cancer surgical outcome. Eur Respir J. 2005:25:594-9.

4. Zhai R, Yu X, Shafer A, Wain JC, Christiani DC. The impact of coexisting COPD on survival of patients with early-stage non-small cell lung cancer undergoing surgical resection. Chest. 2014;145:346-53.

5. Gupta H, Ramanan B, Gupta KP, Fang X, Polich A, Modrykamien A, et al. Impact of COPD on postoperative outcomes: results from a national database. Chest. 2013;143:1599-606.

6. Kim SE, Kim TY, Kang HC, Park KI, Bae W, Choi MS, et al. Prevalence of and risk factors for postoperative pulmonary complications after lung cancer surgery in patients with early-stage COPD. Int J Chron Obstruct Pulmon Dis. 2016;11:1317-26.

7. Yoshida Y, Kage H, Murakawa T, Sato Y, Ota S, Fukayama M, et al. Worse prognosis for stage ia lung cancer patients with smoking history and more severe chronic obstructive pulmonary disease. Ann Thorac Cardiovasc Surg. 2015;21:194-200.

8. Bolukbas S, Eberlein M, Eckhoff J, Schirren J. Short-term effects of inhalative tiotropium/formoterol/budenoside versus tiotropium/formoterol in patients with newly diagnosed chronic obstructive pulmonary disease requiring surgery for lung cancer: a prospective randomized trial. Eur J Cardiothorac Surg. 2011;39:995-1000.

9. Roux E, Molimard M, Savineau JP, Marthan R. Muscarinic stimulation of airway smooth muscle cells. Gen Pharmacol. 1998;31:349-56.

10. Cazzola M, Molimard M. The scientific rationale for combining long-acting beta2-agonists and muscarinic antagonists in COPD. Pulm Pharmacol Ther. 2010;23:257-67.

11. Ficker JH, Rabe KF, Welte T. Role of dual bronchodilators in COPD: a review of the current evidence for indacaterol/glycopyrronium. Pulm Pharmacol Ther. 2017:45:19-33.

12. Singh D, Agusti A, Anzueto A, Barnes JP, Bourbeau J, Celli RB, et al. Global strategy for the diagnosis, management, and prevention of chronic obstructive lung disease: the GOLD science committee report 2019. Eur Respir J. 2019;53:1900164.

13. Makino T, Otsuka H, Hata Y, Koezuka S, Azuma Y, Isobe K, et al. Longacting muscarinic antagonist and long-acting beta2-agonist therapy to optimize chronic obstructive pulmonary disease prior to lung cancer surgery. Mol Clin Oncol. 2018:8:647-52.

14. Ueda K, Tanaka T, Hayashi M, Hamano K. Role of inhaled tiotropium on the perioperative outcomes of patients with lung cancer and chronic obstructive pulmonary disease. Thorac Cardiovasc Surg. 2010;58:38-42.

15. Kobayashi S, Suzuki S, Niikawa H, Sugawara T, Yanai M. Preoperative use of inhaled tiotropium in lung cancer patients with untreated COPD. Respirology. 2009;14:675-9.

16. Suissa S, Dell'Aniello S, Ernst P. Comparative effects of LAMA-LABA-ICS vs LAMA-LABA for COPD: cohort study in real-world clinical practice. Chest. 2020;157:846-55.

17. Shekar K, Foot C, Fraser J, Ziegenfuss M, Hopkins P, Windsor M. Bronchopleural fistula: an update for intensivists. J Crit Care. 2010;25:47-55. 
18. Sekine Y, Yamada Y, Chiyo M, Iwata T, Nakajima T, Yasuhuku K, et al. Association of chronic obstructive pulmonary disease and tumor recurrence in patients with stage IA lung cancer after complete resection. Ann Thorac Surg. 2007:84:946-50.

19. Lourenço RV, Klimek MF, Borowski CJ. Deposition and clearance of 2 micron particles in the tracheobronchial tree of normal subjects-smokers and nonsmokers. J Clin Investig. 1971;50:1411-20.

20. Galaris D, Evangelou A. The role of oxidative stress in mechanisms of metal-induced carcinogenesis. Crit Rev Oncol Hematol. 2002;42:93-103.

21. Schwartz AG, Ruckdeschel JC. Familial lung cancer: genetic susceptibility and relationship to chronic obstructive pulmonary disease. Am J Respir Crit Care Med. 2006;173:16-22.

22. Wollin L, Pieper MP. Tiotropium bromide exerts anti-inflammatory activity in a cigarette smoke mouse model of COPD. Pulm Pharmacol Ther. 2010;23:345-54.
23. Song P, Sekhon HS, Fu XW, Maier M, Jia Y, Duan J, et al. Activated cholinergic signaling provides a target in squamous cell lung carcinoma. Cancer Res. 2008;68:4693-700.

24. Li H, Tong CW, Leung Y, Wong MH, To KK, Leung KS. Identification of clinically approved drugs indacaterol and canagliflozin for repurposing to treat epidermal growth factor tyrosine kinase inhibitor-resistant lung cancer. Front Oncol. 2017;7:288.

\section{Publisher's Note}

Springer Nature remains neutral with regard to jurisdictional claims in published maps and institutional affiliations.
Ready to submit your research? Choose BMC and benefit from:

- fast, convenient online submission

- thorough peer review by experienced researchers in your field

- rapid publication on acceptance

- support for research data, including large and complex data types

- gold Open Access which fosters wider collaboration and increased citations

- maximum visibility for your research: over 100M website views per year

At BMC, research is always in progress.

Learn more biomedcentral.com/submissions 